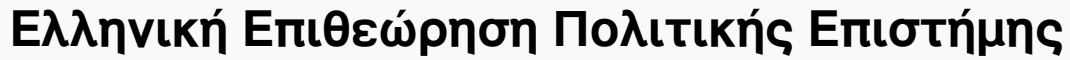

Tón. 28, Ap. 1 (2006)

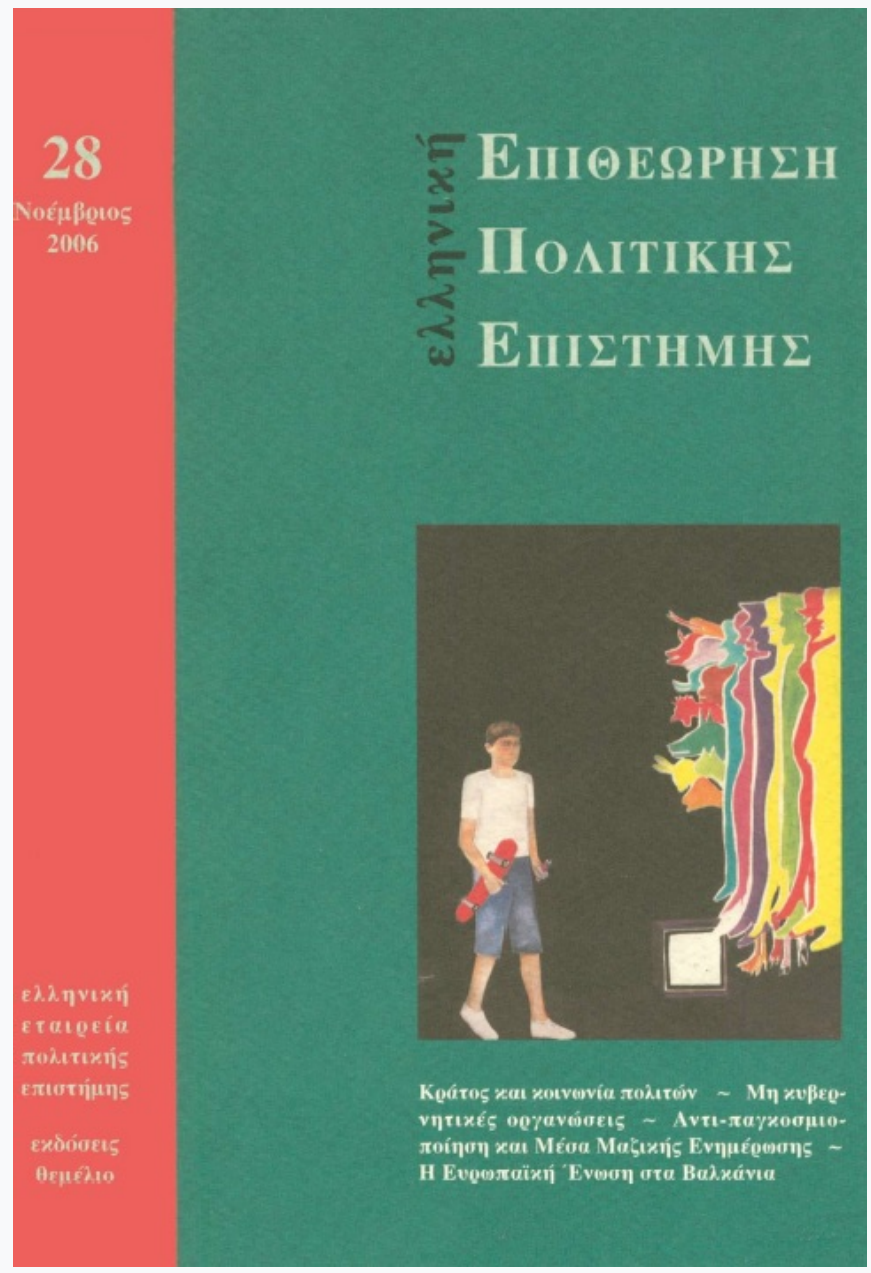

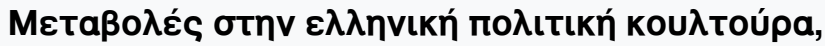

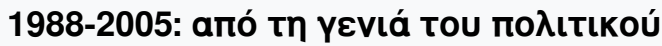

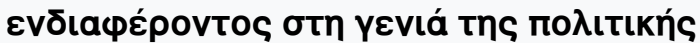
aర̃ıpopías;

\section{Mavíva Какєпа́кn}

doi: $\underline{10.12681 / h p s a .14664}$

\section{Copyright @ 2017, Mavíva Kaкєnákn}

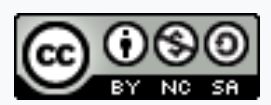

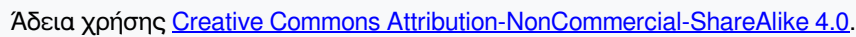

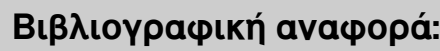

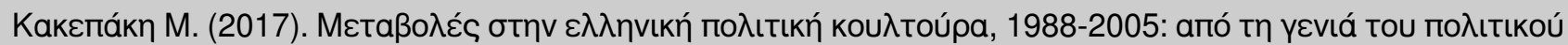

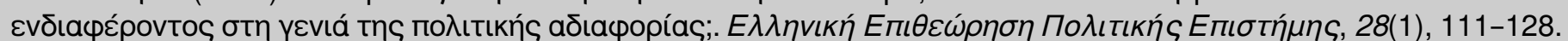
https://doi.org/10.12681/hpsa.14664 


\section{METABO $\Lambda E \Sigma \Sigma T H N$ E $\Lambda \Lambda$ HNIKH \\ ПOАITIKH KOYATOYPA, 1988-2005:

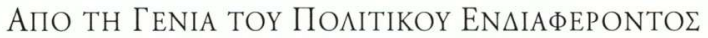

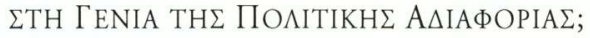

\section{Mavíva Какєпа́кn}

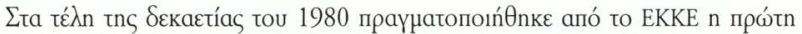

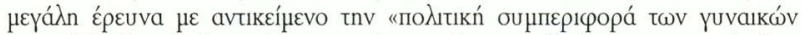

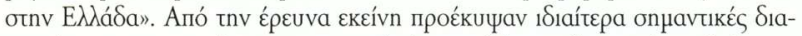

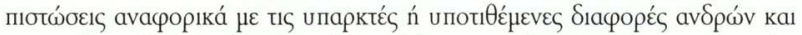

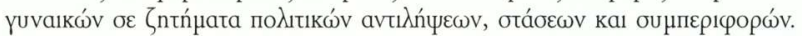

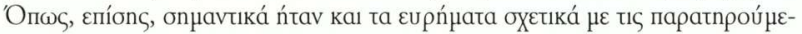

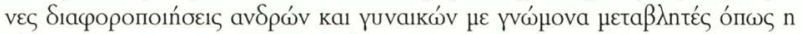

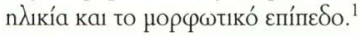

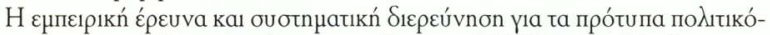

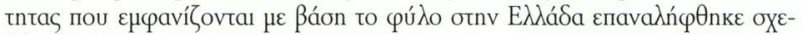

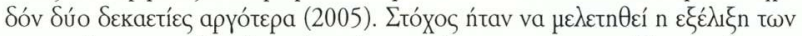

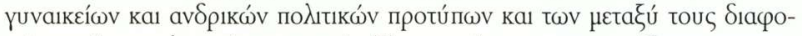

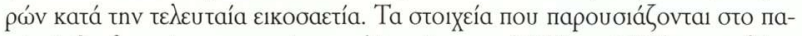

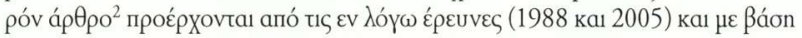

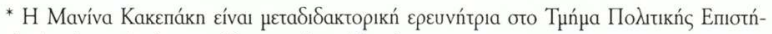

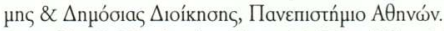

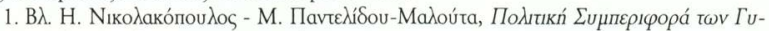

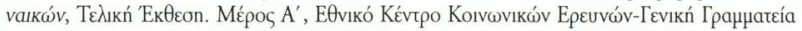

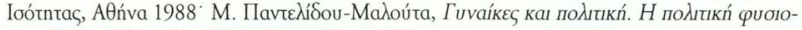

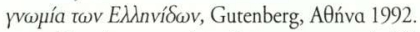

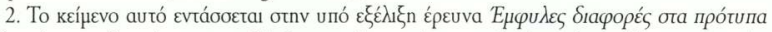

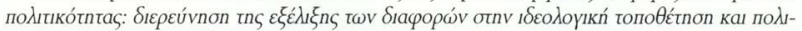

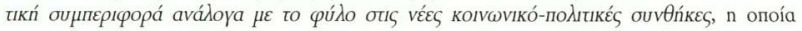

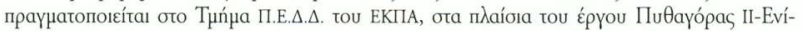

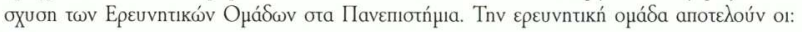




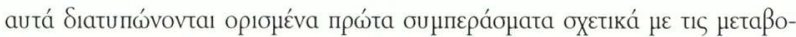

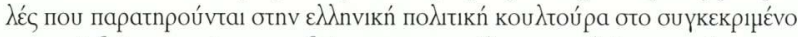

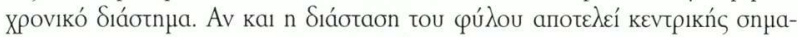

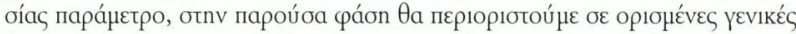

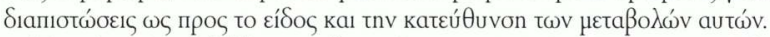

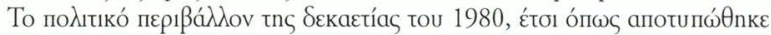

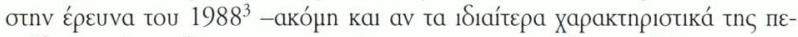

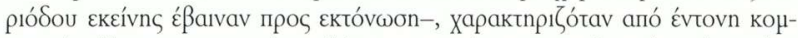

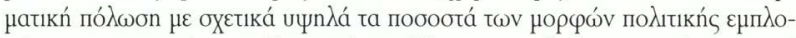

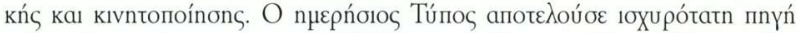

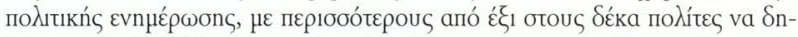

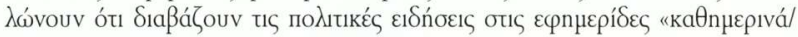

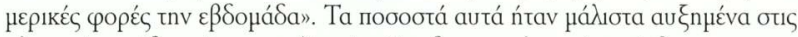

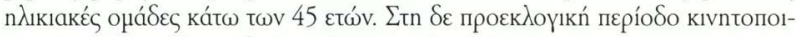

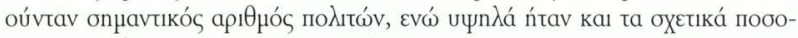

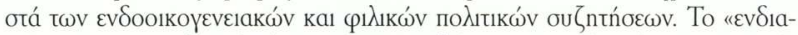

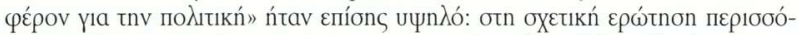

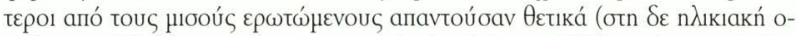

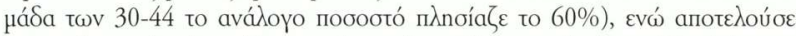

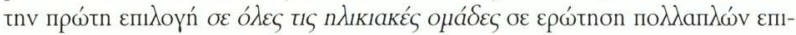

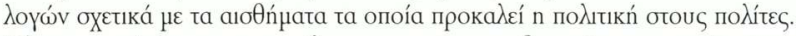

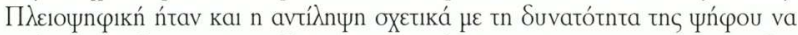

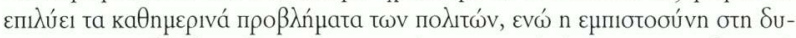

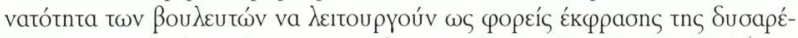

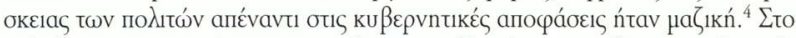

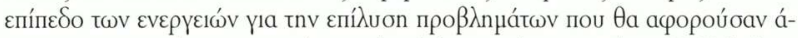

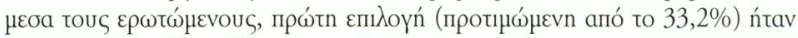

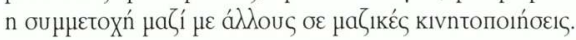

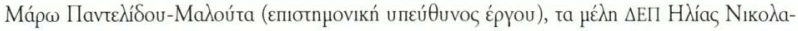
кóпоu

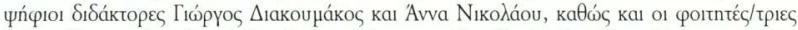

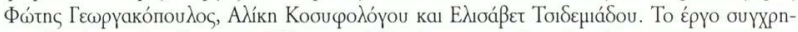

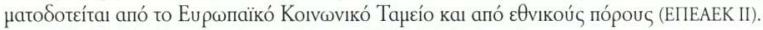

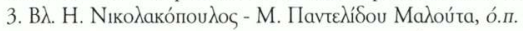

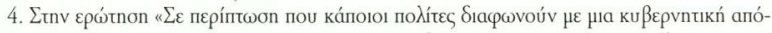

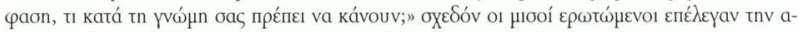

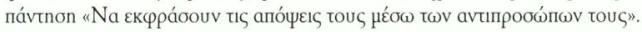




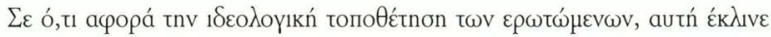

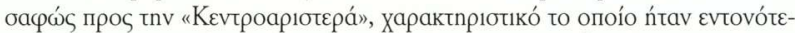

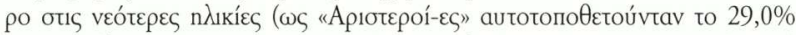

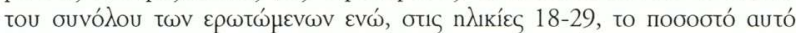

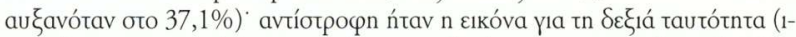

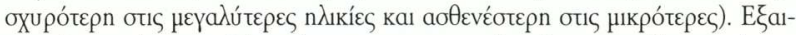

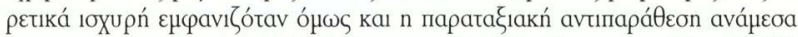

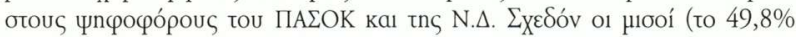

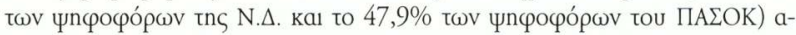

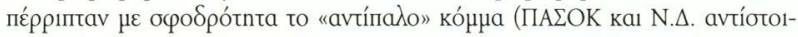

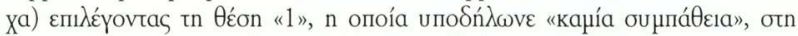

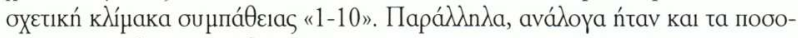

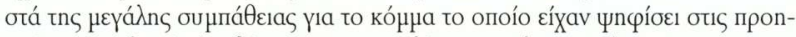

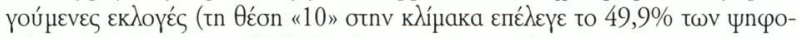

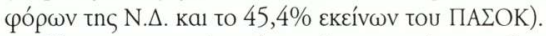

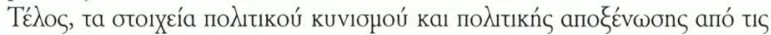

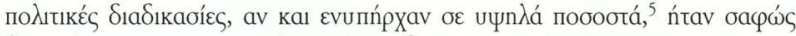

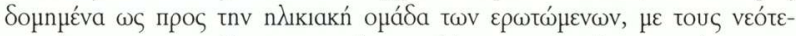

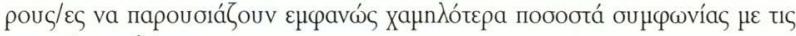

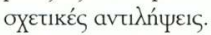

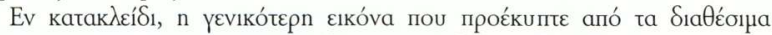

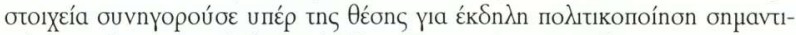

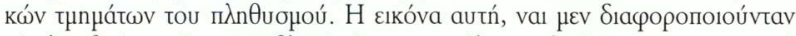

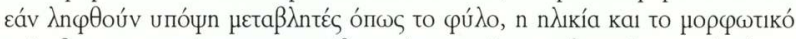

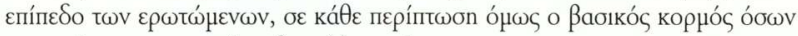

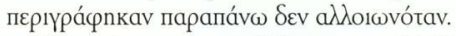

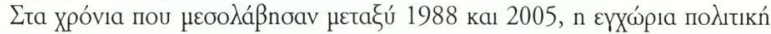

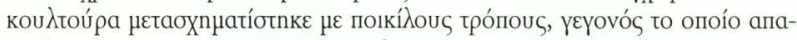

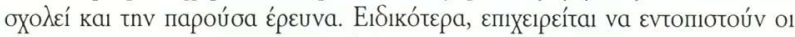

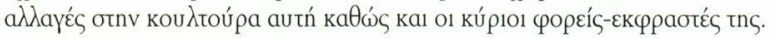

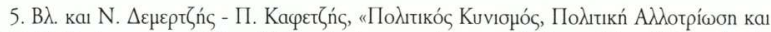

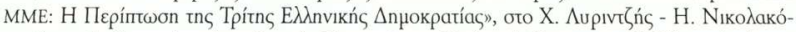

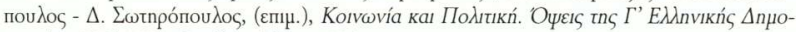

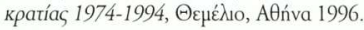




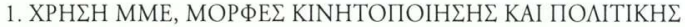 ЕМП ОКН $\Sigma$}

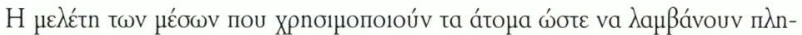

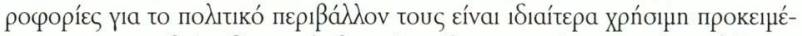

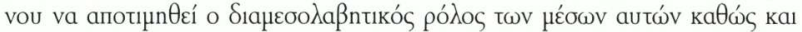

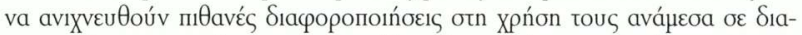

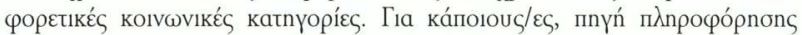

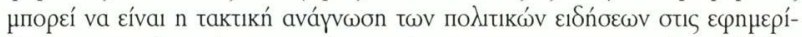

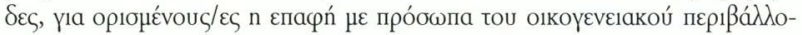

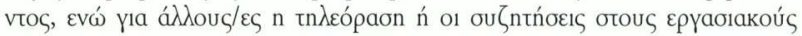

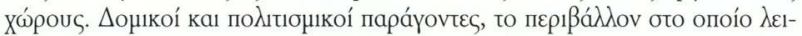

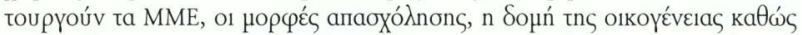

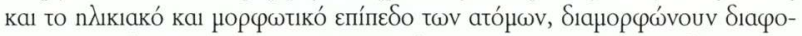

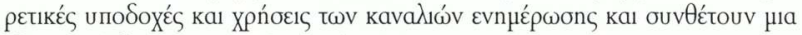

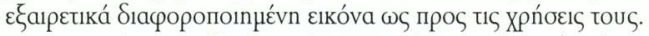

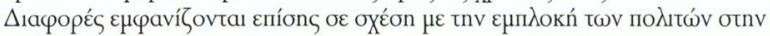

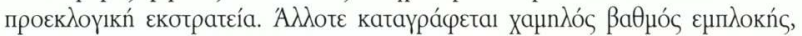

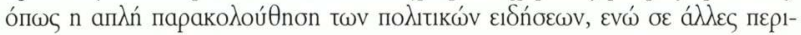

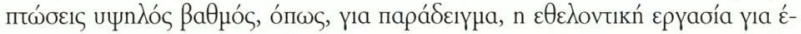

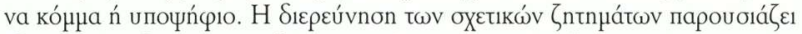

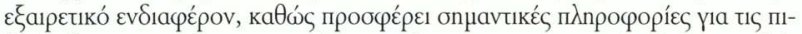

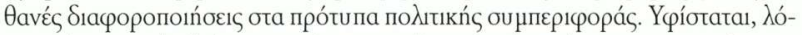

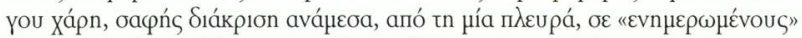

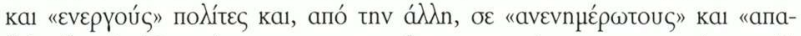
Ө

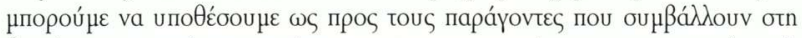

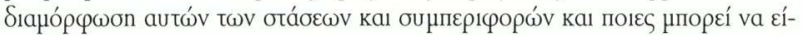

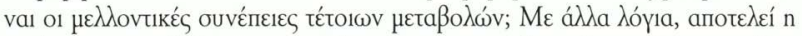

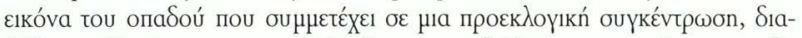

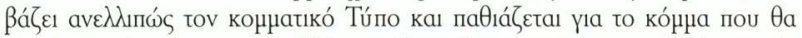

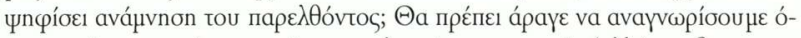

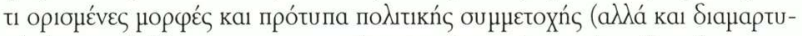

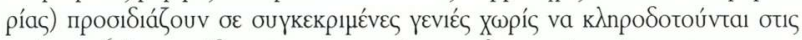

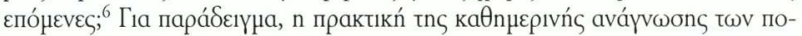

6. B ג. C. Pattie - P. Seyd - P. Whiteley, Citizenship in Britain. Values, Participation and

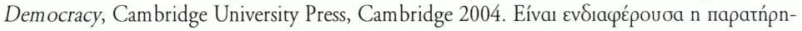




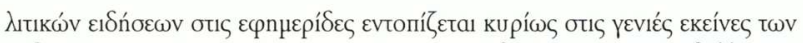

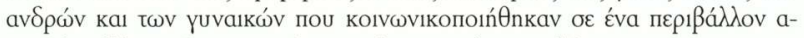

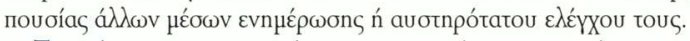

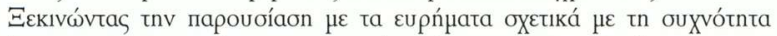

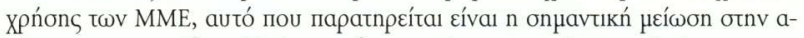

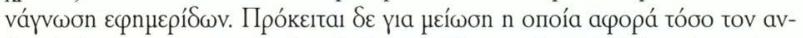

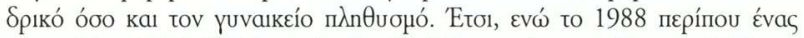

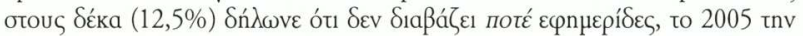

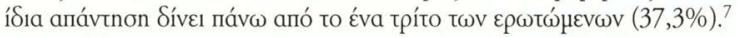

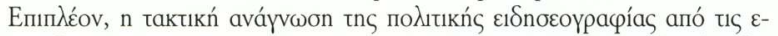

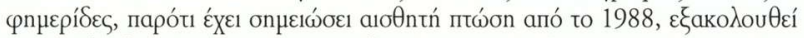

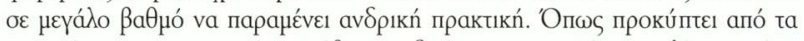

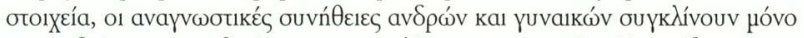

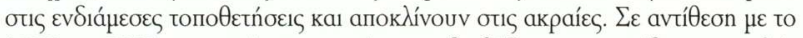

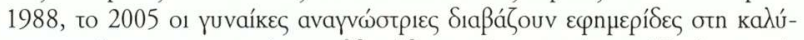

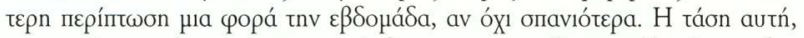
поU

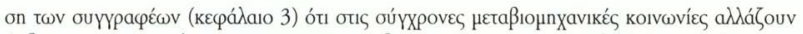

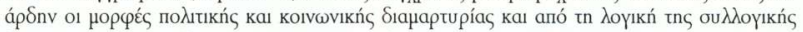

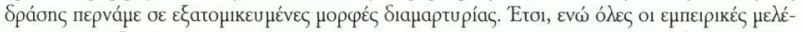

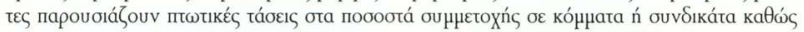

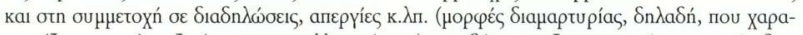

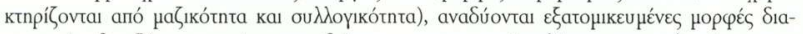

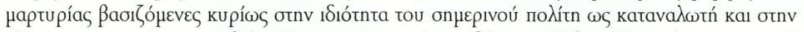

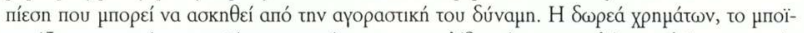

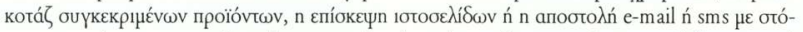

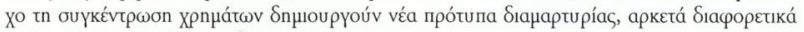

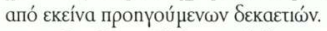

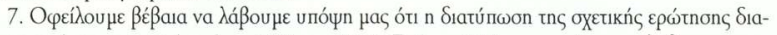

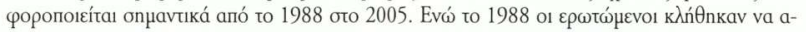

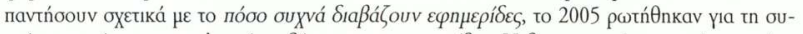

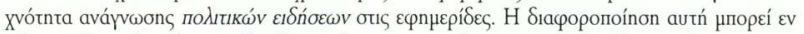

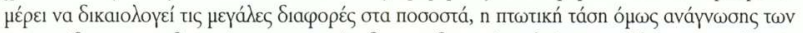
$\varepsilon \varphi n \mu \varepsilon \rho i ́ \delta \omega v$ o

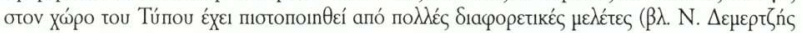

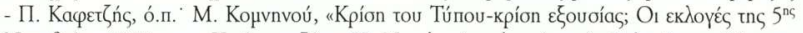

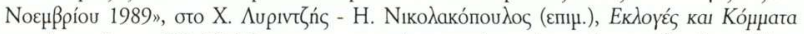

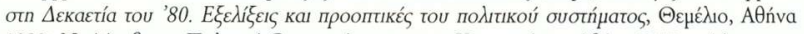

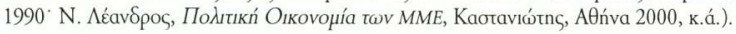




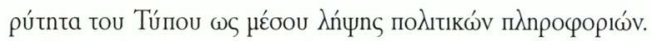

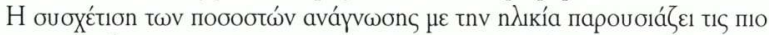

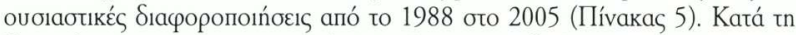

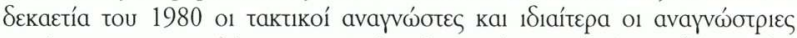

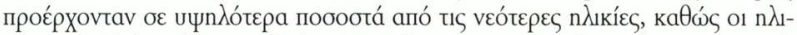

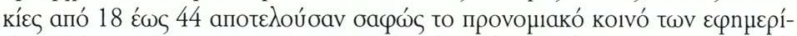

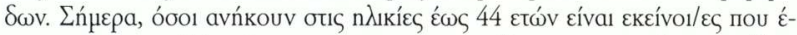

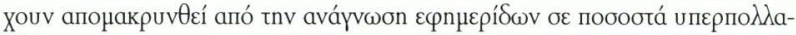

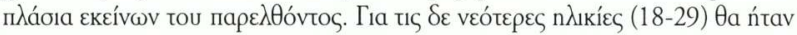

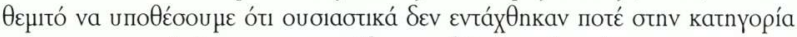

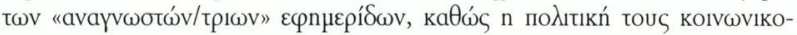

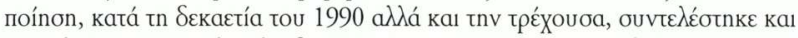

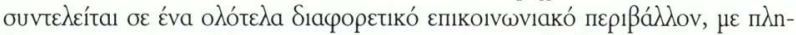

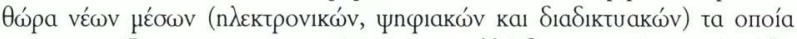

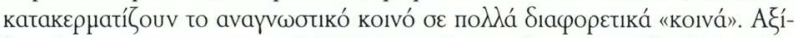

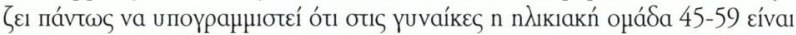

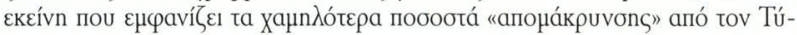

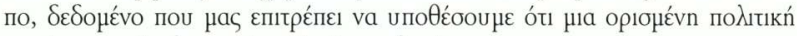

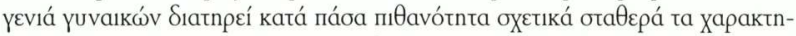

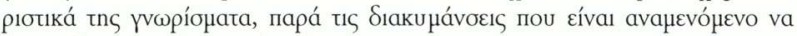

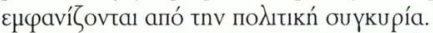

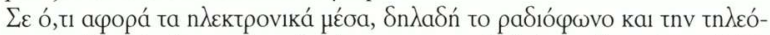

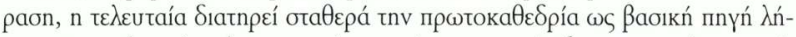

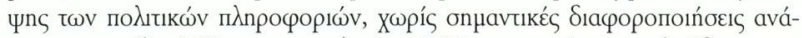

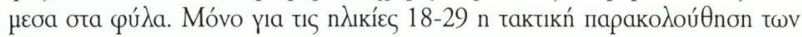

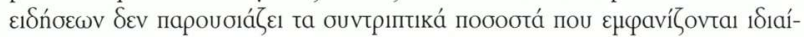

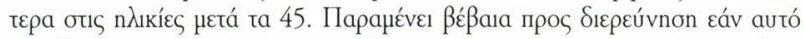

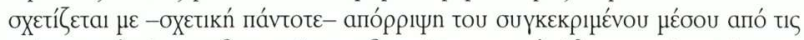

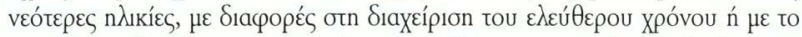

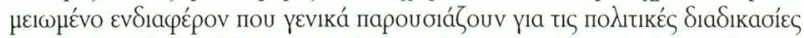

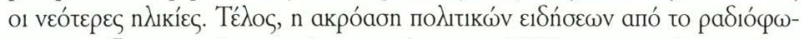

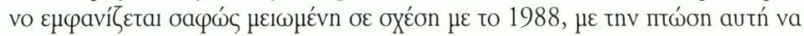

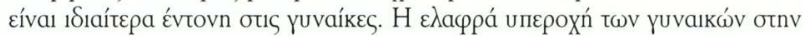

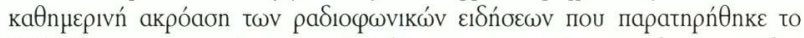

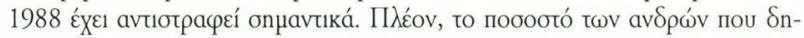

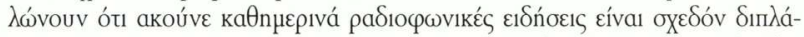

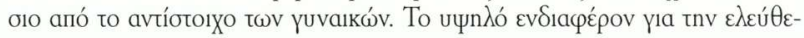




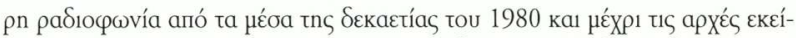

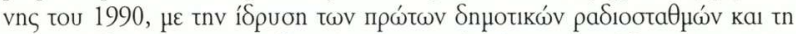

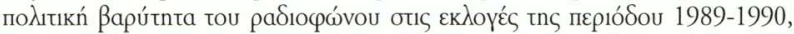

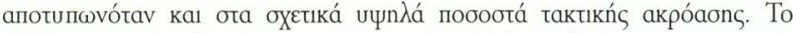

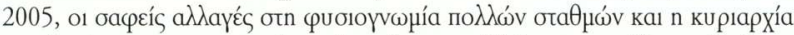

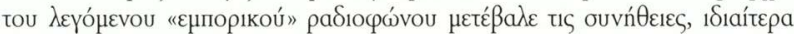

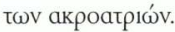

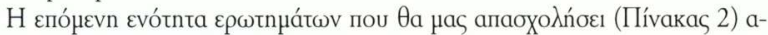

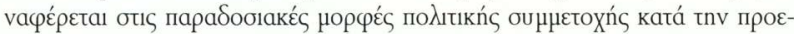

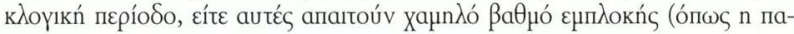

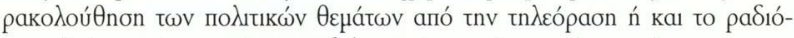

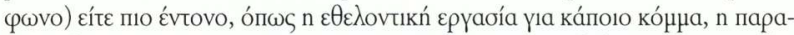

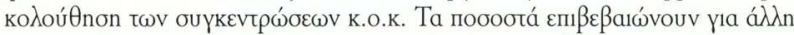

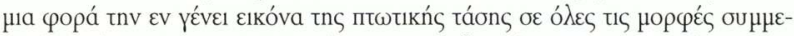

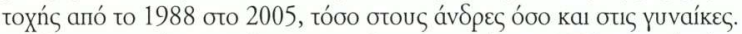

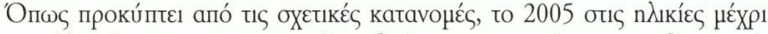

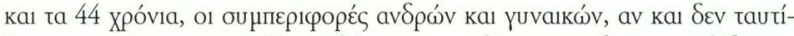

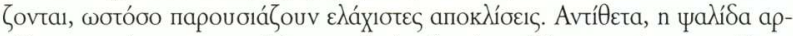

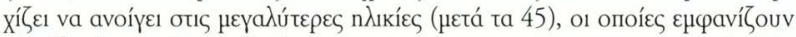

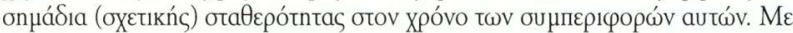

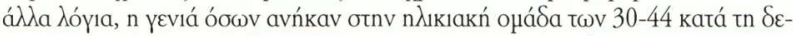

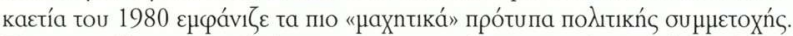

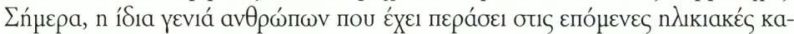

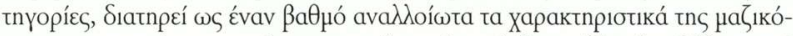

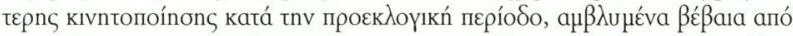

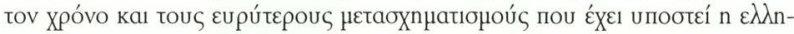

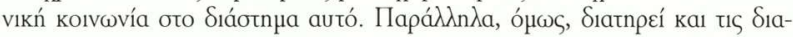

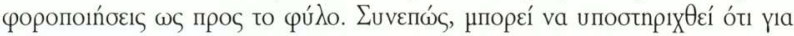

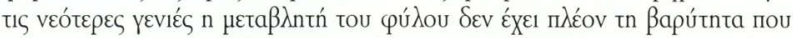

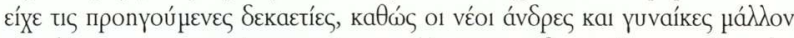

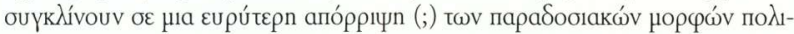

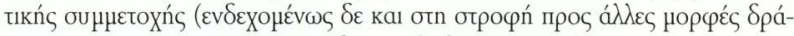

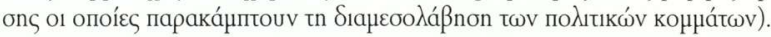




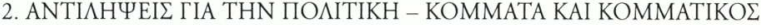

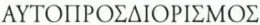

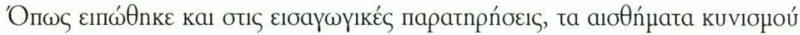

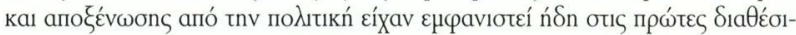

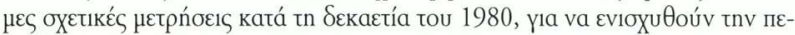

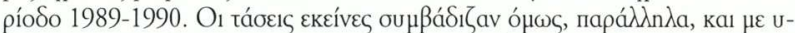

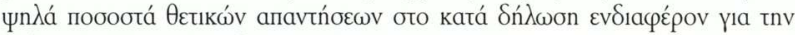

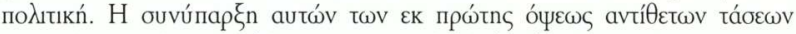

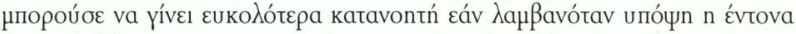

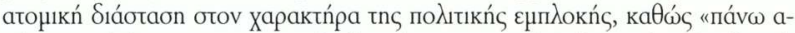

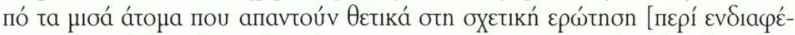

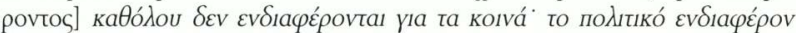

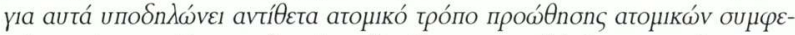

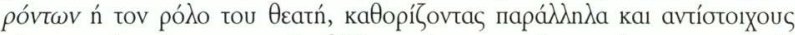

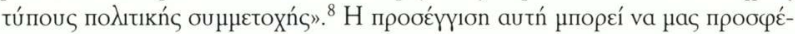

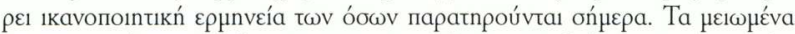

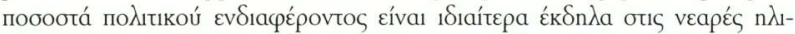

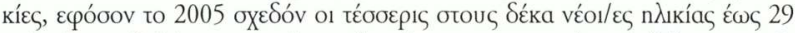

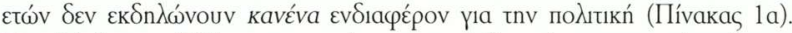

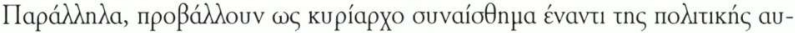

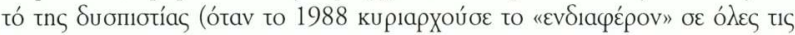

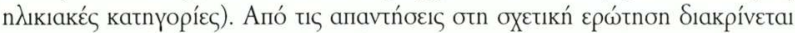

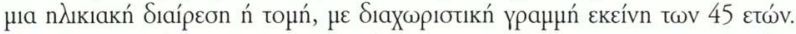

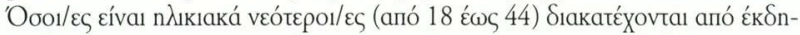

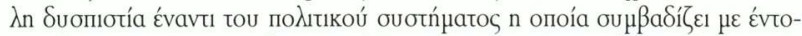

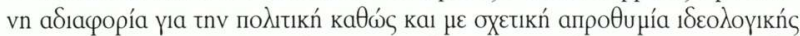

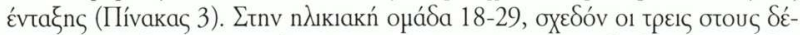

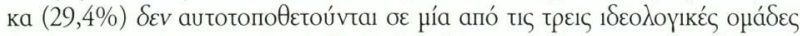

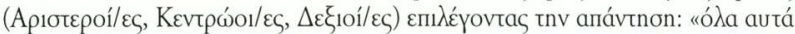

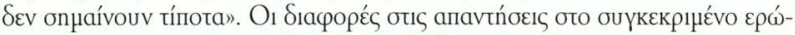

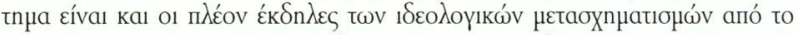

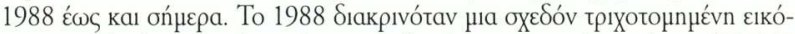

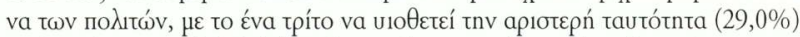

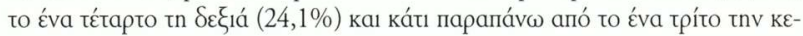

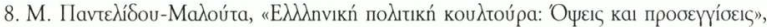

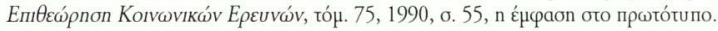




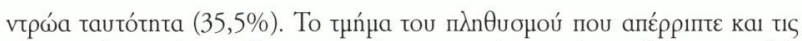

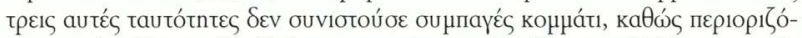

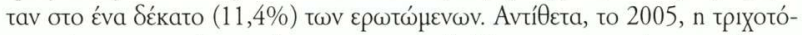

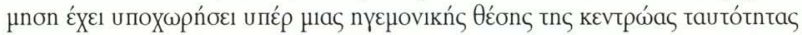

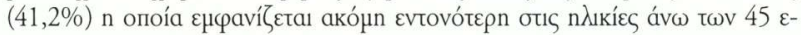

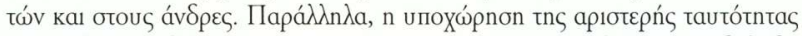

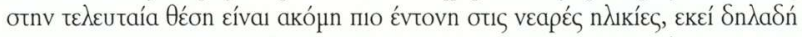

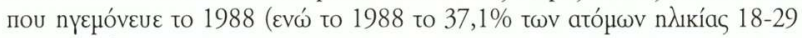

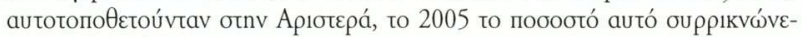
tal oто 9,8\%).

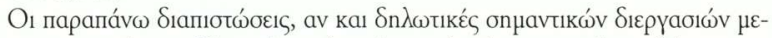

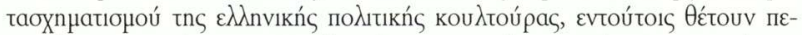

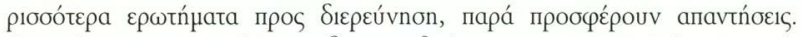

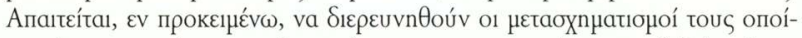

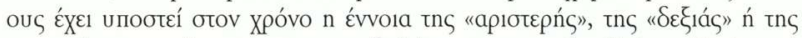

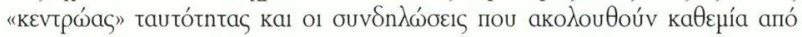

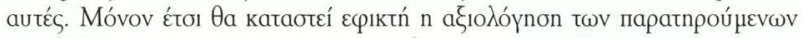

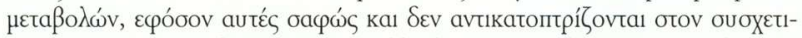

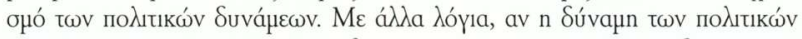

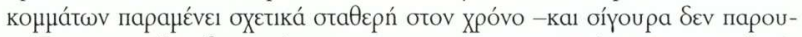

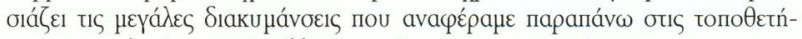

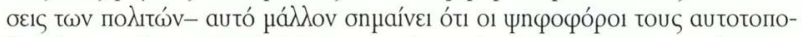

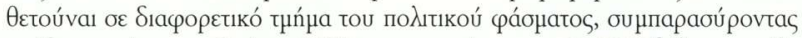

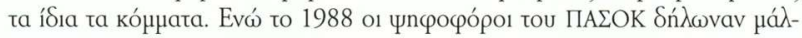

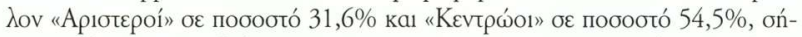

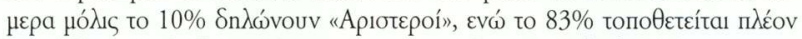

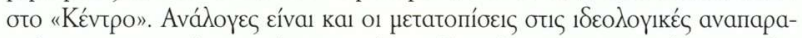

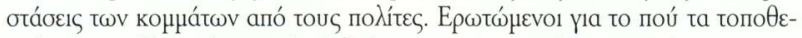

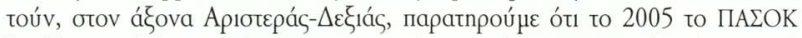

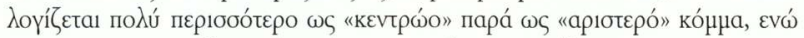

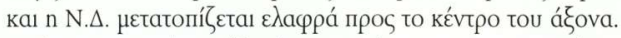

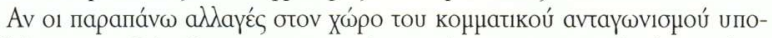

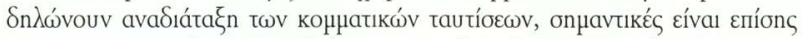

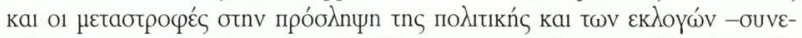

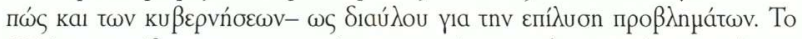

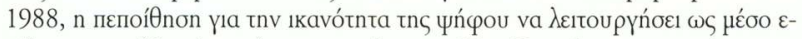

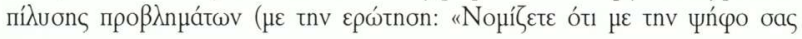




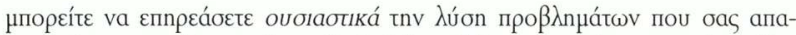

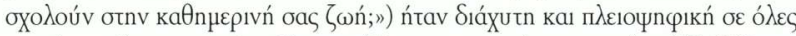

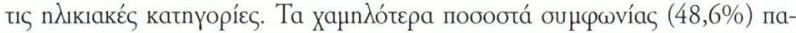

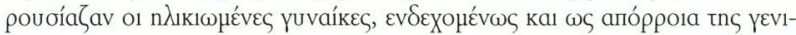
кótepn

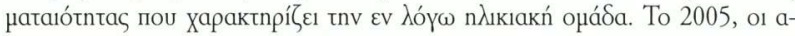

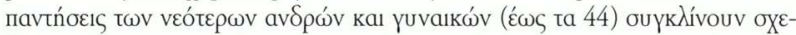

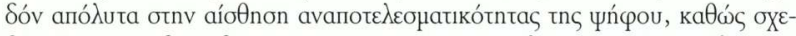

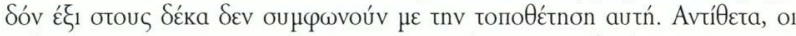

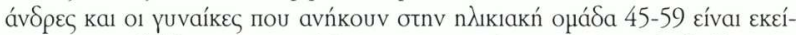

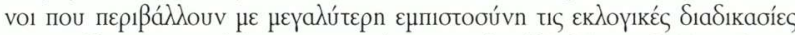

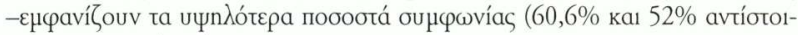

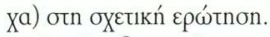

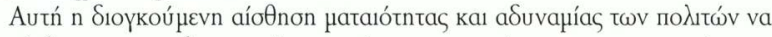

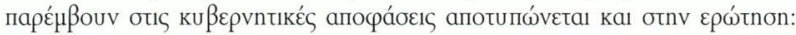

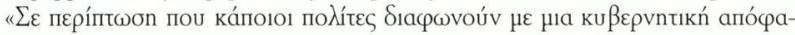

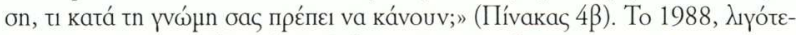

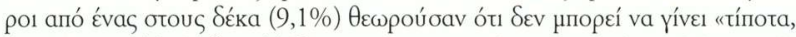

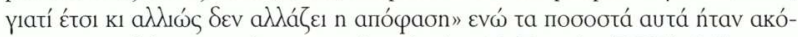

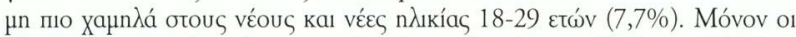

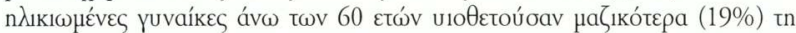

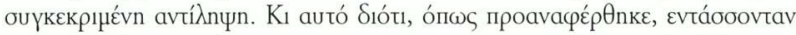

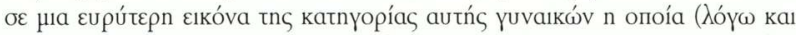

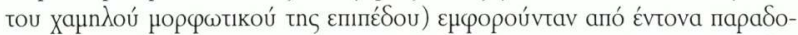

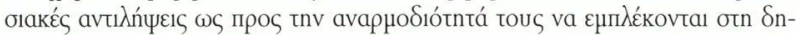

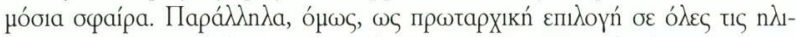

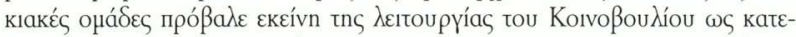

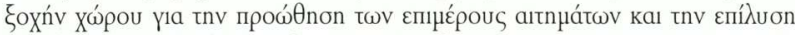

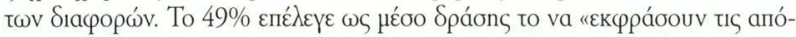

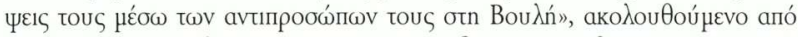

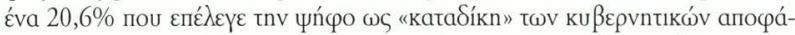

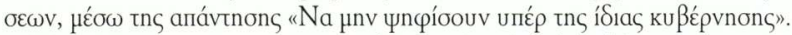

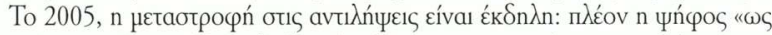

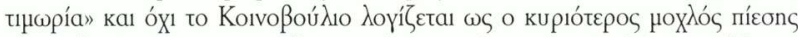

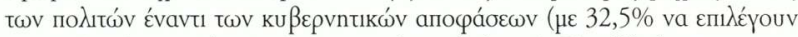

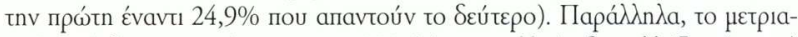

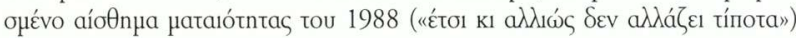




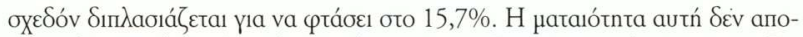

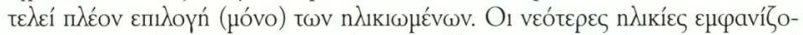

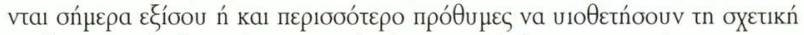

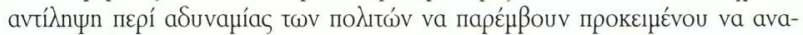

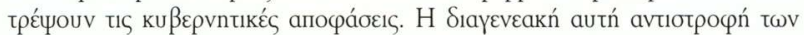

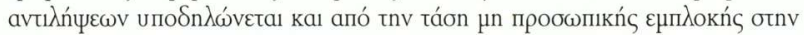

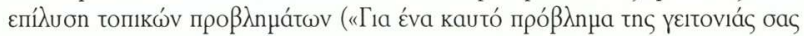

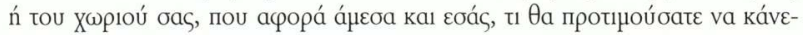

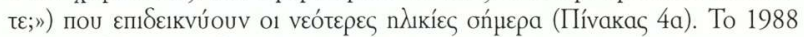

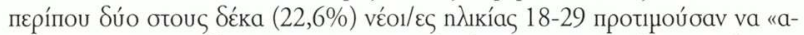

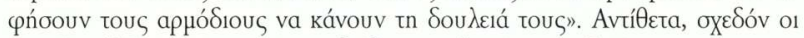

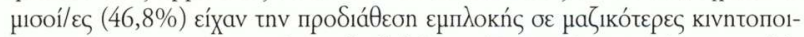

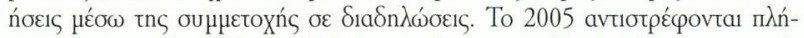

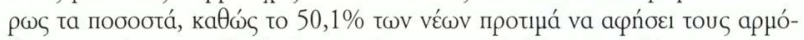

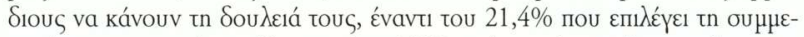

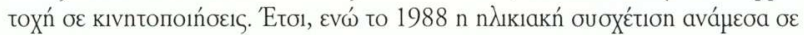

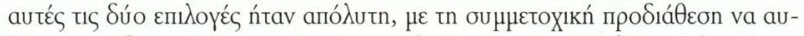

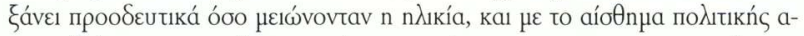

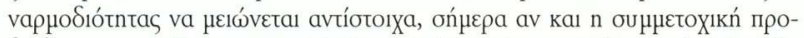

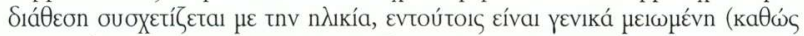

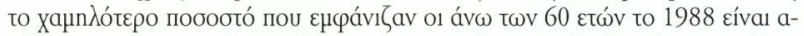

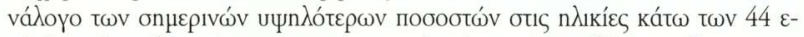

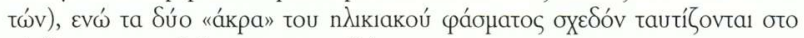

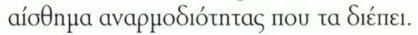

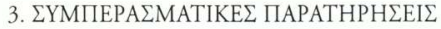

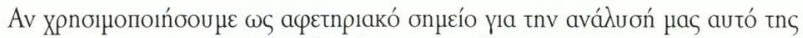

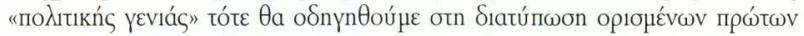

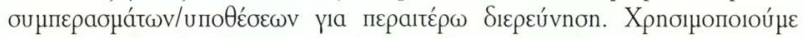

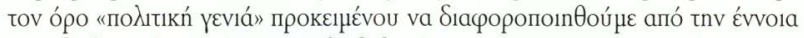

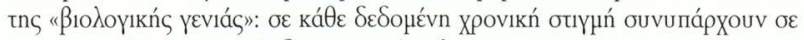

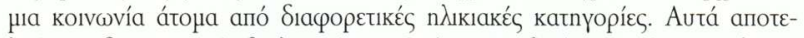

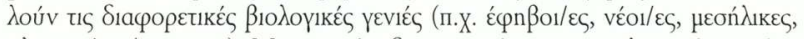

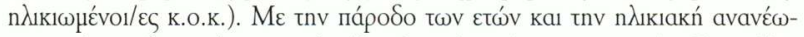

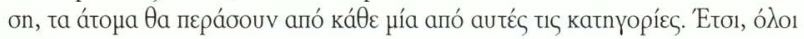




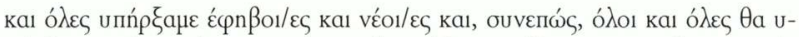

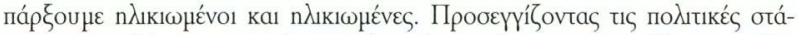

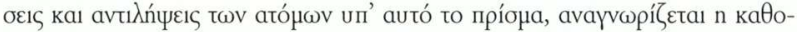

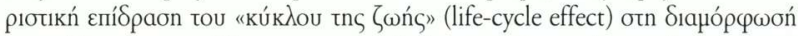

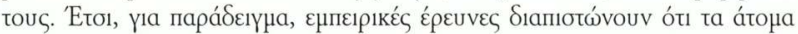

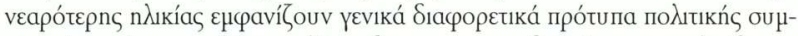

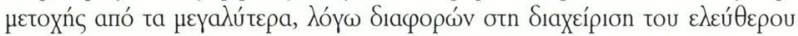

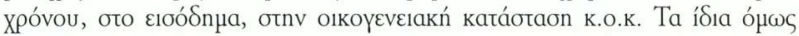

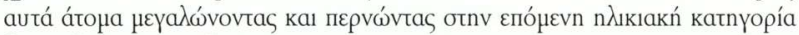

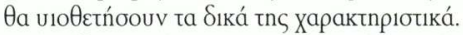

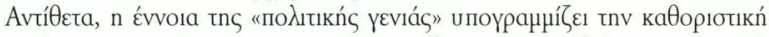

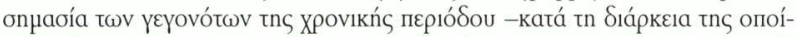

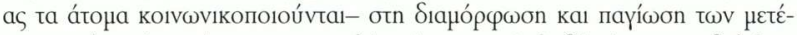

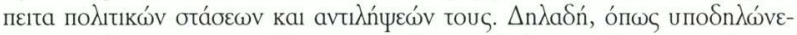

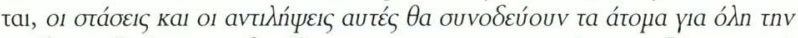

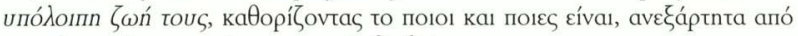

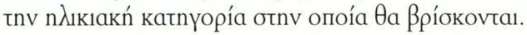

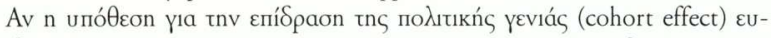

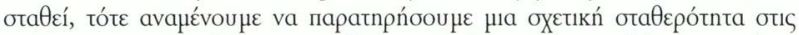

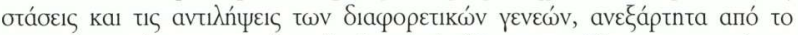

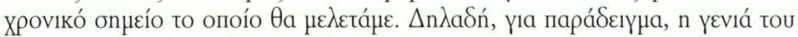

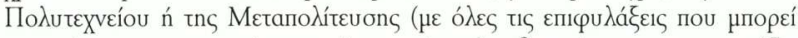

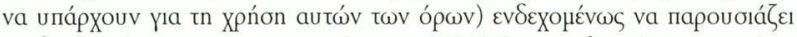

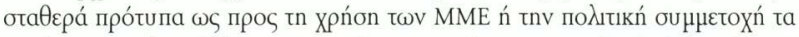

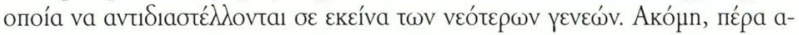

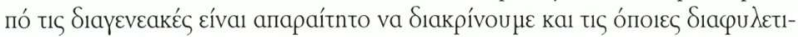

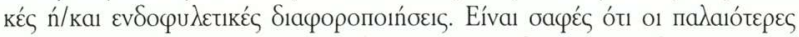

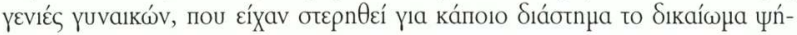

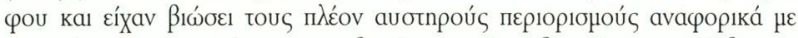

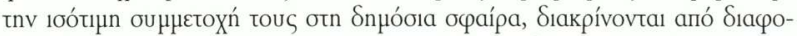

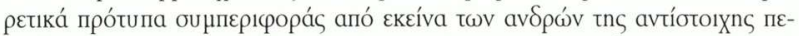

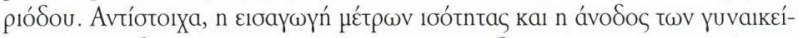

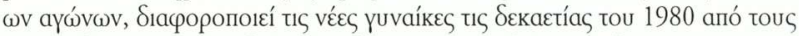

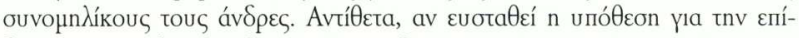

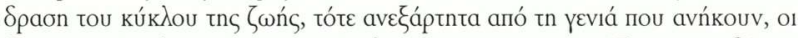

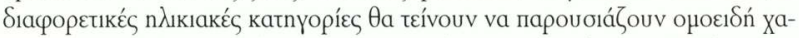

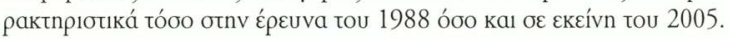




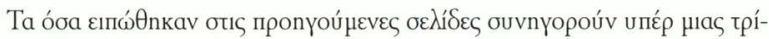

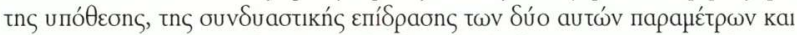

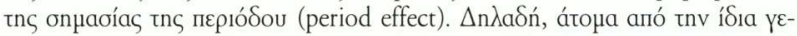

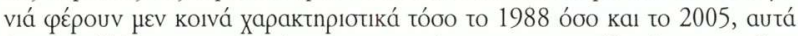

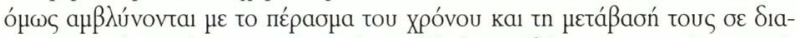

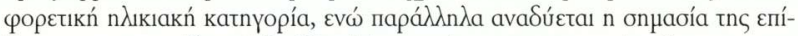

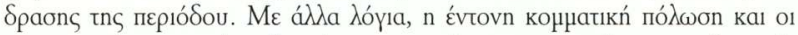

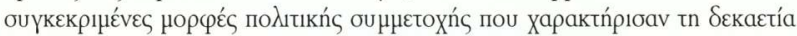

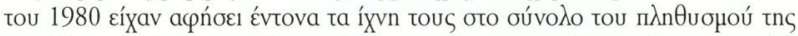

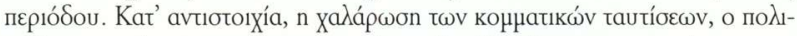

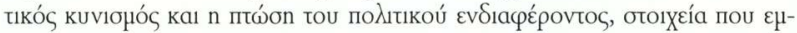

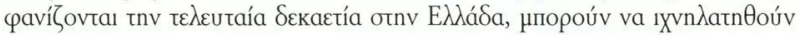

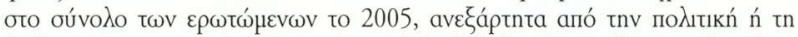

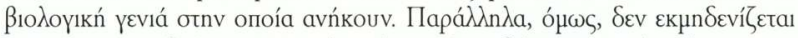

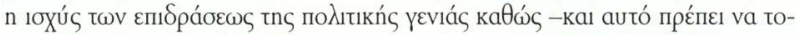

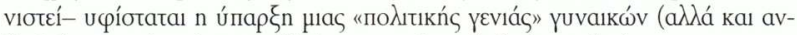

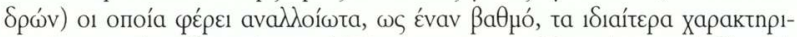

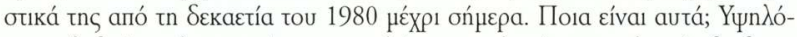

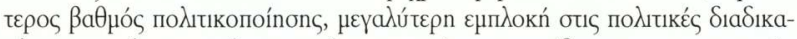

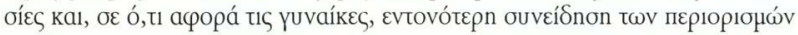

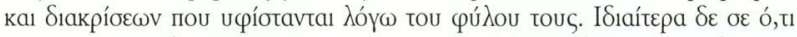

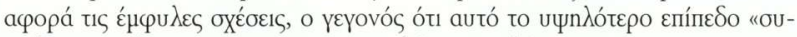

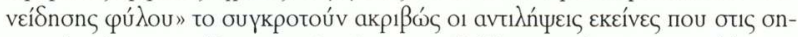

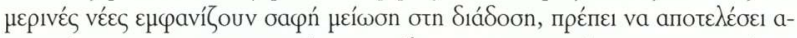

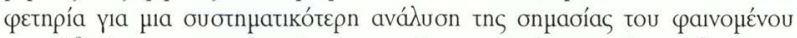

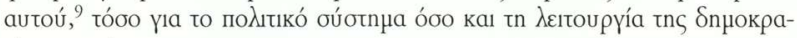
tías үعvıкótepa.

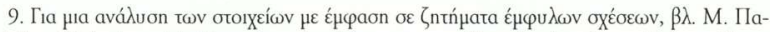

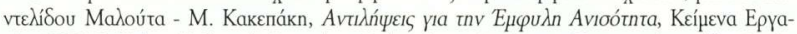

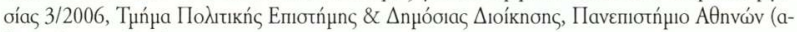

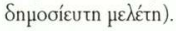




\title{
ПАРАРTHMA ПINAKON
}

\author{
ПINAKA $\Sigma$ 1a
}

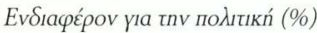

\begin{tabular}{|c|c|c|c|c|}
\hline & \multicolumn{2}{|c|}{ 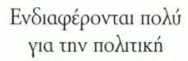 } & \multicolumn{2}{|c|}{ 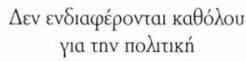 } \\
\hline & 1988 & 2005 & 1988 & 2005 \\
\hline \multicolumn{5}{|l|}{ HAIKIA } \\
\hline $18-29$ & 43,5 & 24,5 & 15,9 & 39,5 \\
\hline $30-44$ & 59,5 & 34,4 & 15,1 & 29,5 \\
\hline $45-59$ & 56,4 & 49,8 & 19,2 & 24,3 \\
\hline $60+$ & 55,0 & 41,2 & 23,1 & 32,5 \\
\hline \multicolumn{5}{|l|}{$\Phi Y \Lambda O$} \\
\hline Гuvaíkes & 13,6 & 7,3 & 21,9 & 38,8 \\
\hline 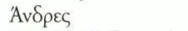 & 26,0 & 15,2 & 15,0 & 23,8 \\
\hline 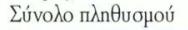 & 53,6 & 37,6 & 18,4 & 31,3 \\
\hline
\end{tabular}

ПINAKA $1 \beta$

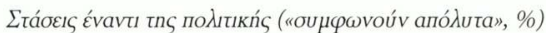

\begin{tabular}{|c|c|c|c|c|c|c|}
\hline & \multicolumn{2}{|c|}{ 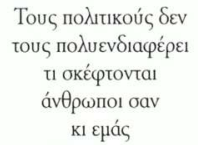 } & \multicolumn{2}{|c|}{ 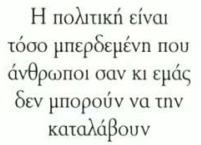 } & \multicolumn{2}{|c|}{ 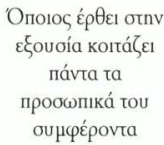 } \\
\hline & 1988 & 2005 & 1988 & 2005 & 1988 & 2005 \\
\hline \multicolumn{7}{|l|}{ HАIKIA } \\
\hline $18-29$ & 43,1 & 58,6 & 37,6 & 29,4 & 49,0 & 70,6 \\
\hline $30-44$ & 45,7 & 57,9 & 37,9 & 25,0 & 53,8 & 69,6 \\
\hline $45-59$ & 55,1 & 54,4 & 54,1 & 28,0 & 66,0 & 63,7 \\
\hline $60+$ & 54,9 & 59,4 & 59,8 & 34,9 & 70,2 & 66,9 \\
\hline \multicolumn{7}{|l|}{ ФYАO } \\
\hline Гuvaíkes & 50,8 & 61,2 & 54,0 & 33,0 & 63,6 & 72,2 \\
\hline 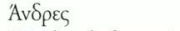 & 48,7 & 54,2 & 41,1 & 25,6 & 56,3 & 63,0 \\
\hline 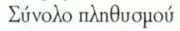 & 49,8 & 57,7 & 47,5 & 29,3 & 59,9 & 67,7 \\
\hline
\end{tabular}




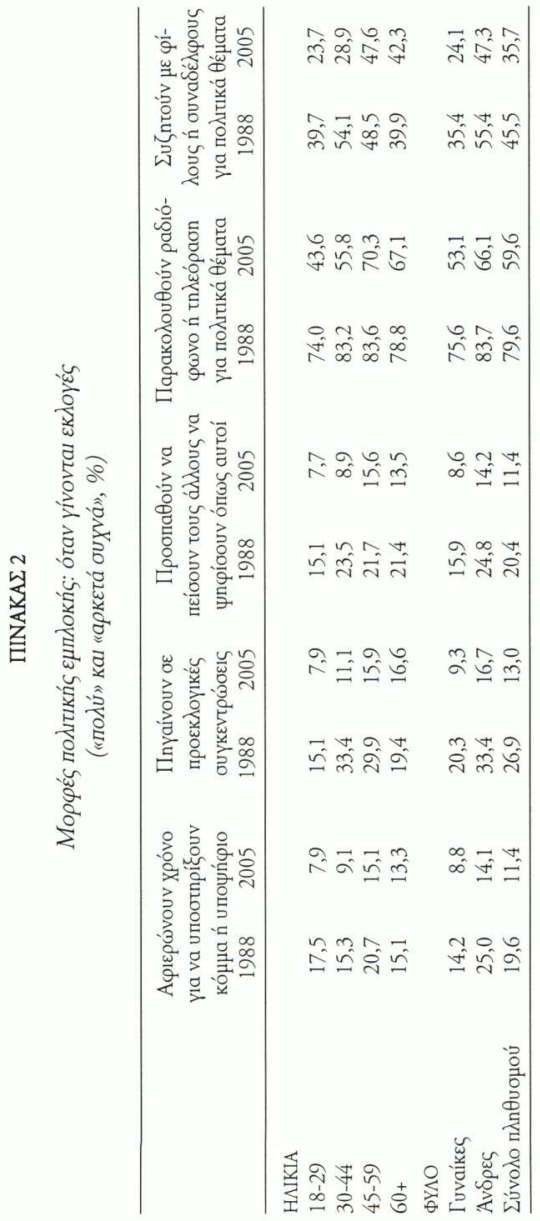


MINAKA 3

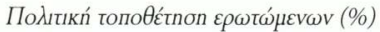

\begin{tabular}{|c|c|c|c|c|c|c|c|c|}
\hline & \multicolumn{2}{|c|}{ 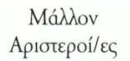 } & \multicolumn{2}{|c|}{ 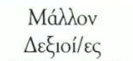 } & \multicolumn{2}{|c|}{ 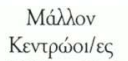 } & \multicolumn{2}{|c|}{ 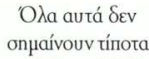 } \\
\hline & 1988 & 2005 & 1988 & 2005 & 1988 & 2005 & 1988 & 2005 \\
\hline \multicolumn{9}{|l|}{ HИIKIA } \\
\hline $18-29$ & 37,1 & 9,8 & 18,4 & 24,1 & 29,8 & 36,6 & 14,7 & 29,4 \\
\hline $30-44$ & 32,8 & 15,3 & 22,4 & 26,2 & 33,9 & 37,8 & 11,0 & 20,7 \\
\hline $45-59$ & 22,8 & 15,9 & 28,3 & 25,6 & 38,3 & 46,8 & 10,4 & 11,8 \\
\hline $60+$ & 23,4 & 13,9 & 27,2 & 37,1 & 40,3 & 43,3 & 9,2 & 5,7 \\
\hline \multicolumn{9}{|l|}{$\Phi Y \Lambda O$} \\
\hline Гuvaíkes & 27,2 & 13,5 & 28,0 & 30,5 & 32,8 & 39,0 & 11,9 & 16,6 \\
\hline Av $\delta \rho \varepsilon \varsigma$ & 30,6 & 14,1 & 20,4 & 26,7 & 38,1 & 43,4 & 10,8 & 15,8 \\
\hline 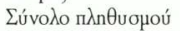 & 29,0 & 13,9 & 24,1 & 28,6 & 35,5 & 41,2 & 11,4 & 16,2 \\
\hline
\end{tabular}

MINAKA乏 4a

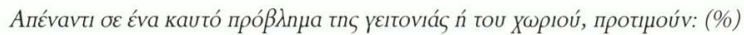

\begin{tabular}{|c|c|c|c|c|c|c|c|c|}
\hline & \multicolumn{2}{|c|}{ 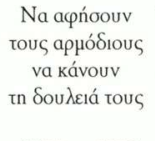 } & \multicolumn{2}{|c|}{ 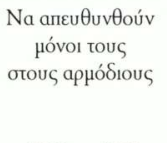 } & \multicolumn{2}{|c|}{ 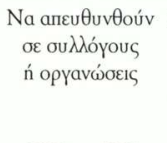 } & \multicolumn{2}{|c|}{ 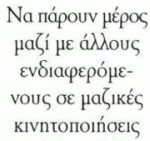 } \\
\hline & 1988 & 2005 & 1988 & 2005 & 1988 & 2005 & 1988 & 2005 \\
\hline \multicolumn{9}{|l|}{ H $\Lambda I K I A$} \\
\hline $18-29$ & 22,9 & 50,1 & 19,8 & 23,4 & 10,9 & 5,1 & 46,8 & 21,4 \\
\hline $30-44$ & 24,5 & 35,6 & 27,3 & 35,2 & 10,5 & 9,7 & 37,7 & 19,5 \\
\hline $45-59$ & 34,0 & 37,2 & 28,0 & 33,1 & 8,9 & 12,6 & 29,0 & 17,1 \\
\hline $60+$ & 43,7 & 48,8 & 28,2 & 33,2 & 8,5 & 4,8 & 19,6 & 13,2 \\
\hline \multicolumn{9}{|l|}{$\Phi Y \Lambda O$} \\
\hline Гuvaíkes & 38,9 & 46,4 & 21,5 & 29,2 & 8,1 & 7,8 & 31,4 & 16,6 \\
\hline 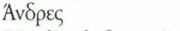 & 23,8 & 38,6 & 30,0 & 34,3 & 11,2 & 8,4 & 34,9 & 18,7 \\
\hline 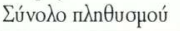 & 31,3 & 42,6 & 25,8 & 31,7 & 9,7 & 8,1 & 33,2 & 17,7 \\
\hline
\end{tabular}




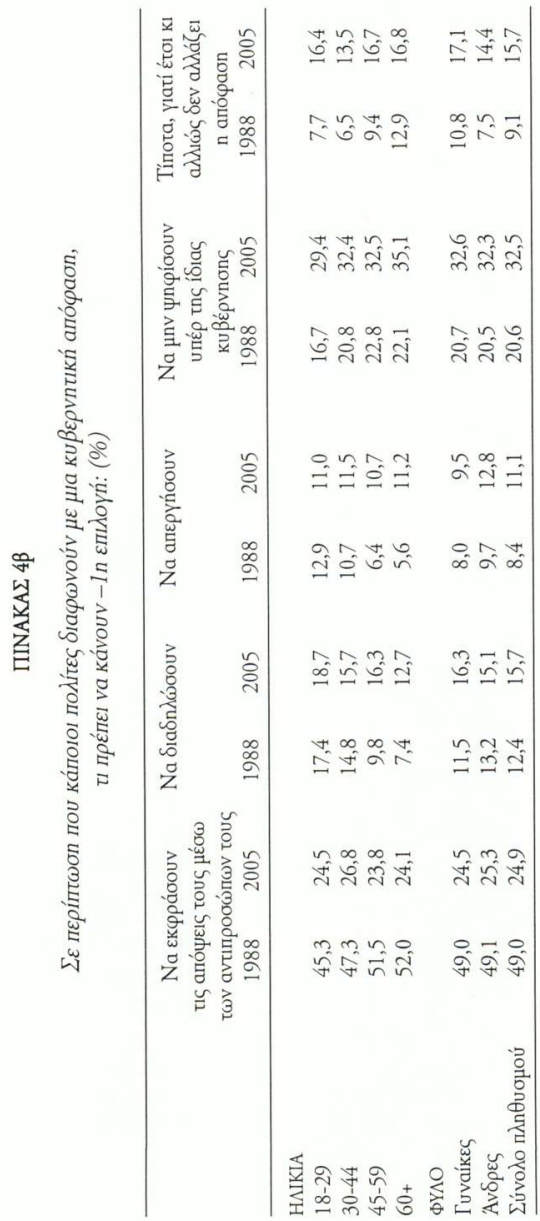




\section{ПINAKAE 5}

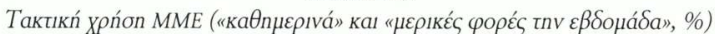

\begin{tabular}{|c|c|c|c|c|c|c|}
\hline & 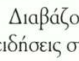 & 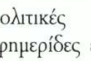 & 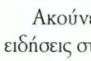 & 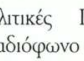 & 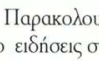 & $\begin{array}{l}\text { Iv подітіке́s } \\
\text { indeópaon }\end{array}$ \\
\hline & 1988 & 2005 & 1988 & 2005 & 1988 & 2005 \\
\hline HAIKIA & & & & & & \\
\hline $18-29$ & 71,8 & 22,4 & 49,3 & 37,3 & 79,4 & 66,0 \\
\hline $30-44$ & 70,4 & 26,0 & 47,4 & 43,1 & 88,0 & 68,2 \\
\hline $45-59$ & 62,3 & 25,8 & 53,9 & 40,6 & 92,4 & 87,2 \\
\hline $60+$ & 51,1 & 20,7 & 54,6 & 27,9 & 88,2 & 87,9 \\
\hline$\Phi Y \Lambda O$ & & & & & & \\
\hline Гuvaíkes & 52,2 & 12,8 & 52,2 & 29,4 & 87,0 & 78,5 \\
\hline$A v \delta \rho \varepsilon \varsigma$ & 75,3 & 34,7 & 50,7 & 44,8 & 87,2 & 81,5 \\
\hline 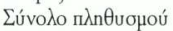 & 's $\quad 63,7$ & 23,8 & 51,5 & 37,1 & 87,0 & 80,1 \\
\hline
\end{tabular}

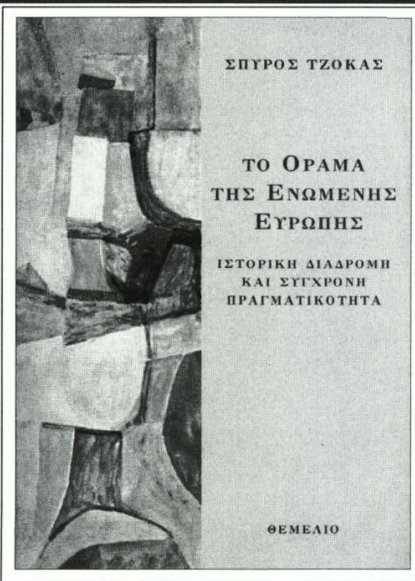

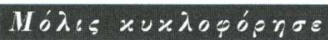

EK $\Delta O \Sigma$ EI $\Sigma \Theta E M E \Lambda$ IO $-\Lambda$ E $\Sigma$ X TOY BIB $\Lambda$ IO

$\Sigma o ́ \lambda \omega \nu o s$ 84, $\tau \eta \lambda .2103608$ 180, 2103602 646, FAX 2103612092 http:/www.themelio-ekdoseis.gr e-mail: info@themelio-ekdoseis.gr 